\title{
EL PRINCIPIO PROTECTOR Y LA REGLA DEL IN DUBIO PRO OPERARIO COMO CRITERIO DE INTERPRETACIÓN DE LA NORMA LABORAL
}

\author{
EnRique Munita LuCo* \\ Abogado
}

\begin{abstract}
RESUMEN: El artículo corresponde a una revisión del principio protector y su manifestación en el in dubio pro operario, tanto desde la perspectiva de la doctrina y jurisprudencia extranjera, principalmente europea continental, como de la doctrina y jurisprudencia nacional. Es posible concluir que el in dubio pro operario no sería un principio del Derecho del Trabajo sino un criterio de interpretación. El in dubio pro operario carecería de vigencia en la doctrina y jurisprudencia europeas. Aun en caso de admitirse su aplicación que debería hacerse de manera muy limitada. Su aplicación introduciría elementos que afectarían la seguridad jurídica. No procedería su utilización para la integración de vacíos legales o para la creación de situaciones no previstas en la ley.
\end{abstract}

Palabras clave: principio protector - in dubio pro operario - interpretación - integración - seguridad jurídica

ABSTRACT: The article consists in the review of the protection principle and its manifestation in the in dubio pro operario, from a foreign, especially continental European law, and Chilean law perspective. It is possible to conclude that the in dubio pro operario is not a principle of Labor Law but only an interpretation criteria. The in dubio pro operario is not considered by the current European doctrine and jurisprudence. Even if estimated possible it should be applied in a very limited way. Its application could create legal uncertainty. It could never be used to fill a legal vacuum or to create situations not considered by the law.

Key words: protection principle - in dubio pro operario - interpretation - legal vacuum filling - legal certainty

\section{EL ORIGEN PROTECTOR DEL DERECHO DEL TRABAJO Y SU EVOLUCIÓN}

El Derecho del Trabajo surge para proteger al trabajador. Esa protección, por la realidad social en que nace, fue más intensa en sus inicios. Con motivo del avance en las condiciones de trabajo la necesidad de protección se ha visto atenuada. La existencia de una avanzada legislación laboral, la actividad sindical y los importantes niveles de protección que en la actualidad otorga el derecho - por la vía judicial y administrativa- se unen a la mayor conciencia de las empresas sobre dignidad de sus trabajadores. En muchos casos el trabajador, por su capacitación y talento, resulta más relevante para la empresa que lo que para éste es un determinado trabajo. No cabe duda que en la actualidad los trabajadores se desempeñan en circunstancias claramente más favorables que lo que ocurría en la primera etapa del siglo veinte e incluso hace unas décadas. Todo ello lleva a matizar la afirmación de la primacía de una de las partes de la relación laboral sobre la otra ${ }^{1}$.

Por otra parte, el Derecho del Trabajo no sólo contiene normas protectoras o tuitivas del trabajador, sino también normas destinadas a proteger los intereses de la empresa y normas neu-

\footnotetext{
- Abogado. Licenciado en Ciencias Jurídicas y Sociales, Universidad de Concepción. Magíster en investigación jurídica, Universidad de los Andes. Profesor del Diplomado Derecho de la empresa, Universidad de los Andes. Contacto: enrique. munita@ppulegal.com

1 Montoya Melgar, Alfredo. Derecho del Trabajo -34 Edición-. Madrid, España: Tecnos, 2013, p. 35.
} 
tras. Esto lleva a matizar construcciones unilateralistas que parecen no considerar la existencia de otra clase de normas. En la relación laboral existen diversos intereses en juego y el derecho debe hacerse cargo de todos ellos. Sin embargo, por la especial dignidad del sujeto que presta los servicios objeto del contrato de trabajo, no se puede obviar su nota distintiva de origen y siempre conserva una orientación social destinada a mantener un punto de equilibrio entre las relaciones del capital con el trabajo.

\title{
2. EL DENOMINADO PRINCIPIO PROTECTOR
}

En la doctrina existe una visión crítica, más bien escéptica, del denominado principio protector. En referencia a los principios del Derecho del Trabajo expresa García-Perrote: "la realidad actual acredita una utilización muy moderada de estos principios que, por lo demás, no son capaces -en realidad nunca lo han sido- de explicar las más complejas interrelaciones de las fuentes de la relación laboral"2. De La Villa Gil dice que "van perdiendo o han perdido ya, parcial o totalmente, su significado y su operatividad originarias". Agrega, "es bastante exacto afirmar que" los denominados principios del derecho del trabajo "o no han sido nunca principios o han dejado ya de serlo". O como diría Mercader: "Los citados 'principios' no son tales"3. De La Villa Gil se explaya sobre la evolución de su pensamiento al respecto:

"Ya desde mis Esquemas de Derecho del Trabajo (Facultad de Derecho de Valencia, edición multicopiada, curso 1971-1972) me pareció imprescindible enmarcar en sus justos límites el favor laboratoris, evitando hacer de él una especie de piedra filosofal para transformar en oro cualquier regulación positiva, fijándole por tanto algunos límites insuperables que se perfilaron luego en la Introducción a la Economía del Trabajo (Debate, vol. I, 1978, pp. 749-750, en colaboración con Manuel Carlos Palomeque López)"4.

En esta última obra concluían que

\begin{abstract}
"No podrán ser objetivos alcanzables por el favor laboratoris la protección de los trabajadores contra el interés público, o contra los intereses legítimos del empleador, ni la creación de instituciones desconocidas por el legislador, ni la variación de la competencia jurisdiccional, ni la invasión del ámbito de las relaciones civiles concertadas entre trabajador y los terceros ni, en definitiva, la rectificación de las deficiencias técnicas cometidas en la formalización de recursos ante el orden social"s.
\end{abstract}

En el derecho francés el denominado príncipe de faveur opera cuando existe concurso normativo, entre ley y contratos colectivos o entre contratos colectivos de diferente nivel, se aplica la

\footnotetext{
2 Garcia-Perrote Escartín, Ignacio. Manual de Derecho del Trabajo -3a Edición-. Valencia, Espana: Tirant Lo Blanch, p. 109.

3 Mercader Uguina, Jesús R.. Los principios de aplicación del Derecho del Trabajo. Valencia, España: Tirant Lo Blanch, 2014 , p. 27.

4 De la Villa Gil, Luis Enrique, "Presentación". En: de la Villa Gil, Luis Enrique; López Cumbre, Lourdes (dir). Los Principios del Derecho del Trabajo. Madrid, España: Centro de Estudios Financieros, 2003, pp. 11 y 12.

$5 \quad$ Ibid. p. 11.
} 
regla más favorable al trabajador o "asalariado" (salarié). Este principio se deduce de las normas que permiten establecer condiciones más favorables para el trabajador en una norma de menor jerarquía ${ }^{6}-_{-}^{7}{ }^{8}$. Sin embargo, este principio no incide en la interpretación ni en la integración normativa.

Lo mismo ocurre en el derecho italiano. El "principio di favore (favor lavoratoris)", permite que, en caso de concurso entre normas de distinta jerarquía, se aplique la norma de menor jerarquía cuando sea más beneficiosa que aquella superior. Al igual que en Francia tiene efectos en la alteración del onus probandi y facilitación de la prueba en situaciones de despido y de discriminación ${ }^{9}{ }^{10}$. Tampoco se utiliza en la interpretación o integración de las normas laborales.

Es decir, en estos derechos más que un denominado principio protector, de dudosa existencia, estaríamos frente a lo que se denomina también principio de condición o norma más favorable que resuelve el problema de jerarquización de fuentes en el Derecho del Trabajo.

Por su parte, en el derecho alemán -además de reiterarse lo expuesto por las doctrinas francesa e italiana- se ha dicho que el Derecho del Trabajo ya no es lo que era en sus orígenes, los intereses de los trabajadores están debidamente representados en el parlamento, en la discusión de las leyes se consideran tanto los intereses de éstos como los de las empresas. Se puede hablar así de una necesaria política del equilibrio. El típico pensamiento protector de la norma tiene un contraprincipio en la promoción del empleo. El intérprete debe respetar la intención parlamentaria, ese debe ser su baremo. La interpretación de las normas laborales debe ser libre de prejuicios pro trabajador o pro empresa, el juez debe buscar la neutralidad interpretativa ${ }^{11}$.

\section{EL IN DUBIO PRO OPERARIO}

Una manifestación del principio protector sería la regla hermenéutica in dubio pro operario. Sobre la misma, su existencia y vigencia, existen serios reparos en la doctrina y jurisprudencia europeas. Invitado a intervenir en el Curso sobre Principios del Ordenamiento Laboral y su Aplicación (Aula de Torrelavega) en Cantabria, julio de 2002, Desdentado-Magistrado de la Sala en lo Social el Tribunal Supremo de España- iniciaba su exposición señalando: "El principio se eclipsa en la práctica judicial y luce cada vez menos en la teoría. No hay sobre él ni monografías, ni menos artículos en revistas especializadas. Comienza a desaparecer en algunos manuales modernos y, aunque en la mayoría se mantiene, se constata en ellos su declive o su carácter problemático". Decía además "tengo la sensación de enfrentarme a una reliquia histórica, a un ejercicio de arqueología jurídica y me temo que este ejercicio pueda resultar algo rancio. Habrá que abordarlo, por lo tanto, con algún humor"'2. El principio pro operario entró en crisis desde hace más de 40 años y "se le considera impropio de una disciplina que ha superado ya su momento inicial; se afirma su

6 Chalaron, Yves. "Lapplication de la disposition la plus favorable". En: Etudes offertes a Gérard Lyon-Caen. Paris, Francia: Dalloz, 1989, p. 243.

7 Cour de Cassation, Rapport de Mme Bardy, Consellier rapporteur, Arret $n^{\circ} 570$ du 24 octobre 2008.

8 Cour de Cassation, Chambre Commercial, 17-07-1996, droit social, p. 1049, J. Sabatier.

9 CessaRI, Aldo. Il favor verso il prestatore di lavoro subordinato. Milan, Italia: A. Giuffre, 1966, p. 33 y ss.

10 Mazzota, Oronzo. “Il diritto del lavoro e le sue fonti”, en: Rivista Italiana di Ditiritto del Lavoro, 3, pp. 219 y ss., Giuffré, 2001 Italia.

1 Hanau, Peter; Adomelt, Klaus. Arbeitsrecht. München, Alemania: Luchterhand, 2007, pp. 28 y 29.

12 Desdentado Bonete, Aurelio. "El Principio Pro Operario". En: De La Villa Gil, Luis Enrique y Lopez Cumbre, Lourdes (dir.). Los Principios del Derecho del Trabajo. Madrid, España: Centro de Estudios Financieros, 2003, pp. 73 y 74. 
incompatibilidad con la imparcialidad del verdadero juez del trabajo; se exige que exista un caso de verdadera duda sobre el alcance de un precepto jurídico aplicable: se considera contrario a la igualdad que garantizan las constituciones"13.

Cessari sostiene que si bien el principio protector podría orientar la creación de normas laborales, no es necesario recurrir a criterios interpretativos peculiares sino que a los criterios generales que conducen casi siempre a conclusiones similares. No cabe concluir la existencia de un criterio especial que lleve a interpretar sistemáticamente las normas en favor del trabajador ${ }^{14}$. Su campo de acción se reduce en la actualidad porque la defensa de los intereses de los trabajadores es "cada vez menos una cuestión de favor o filantropía hermenéutica, que es lo que hay en la raíz del principio pro operario"15. Fue otro

"Laboralista Italiano (GRECO) quien reaccionó enérgicamente contra esta tendencia, estimando lícito y lógico que la legislación social proteja al trabajador, pero oponiéndose a que ese amparo se extienda al juez y constituya para este un mandato casi imperativo para buscar cuanta ocasión se le presente de favorecer a una de las partes, por estimarlo un procedimiento peligrosísimo que hay que manejar con exquisito cuidado"16.

Desdentado ha dicho que "su campo de aplicación es muy limitado y su autonomía cuestionable. Sólo puede aplicarse en relación con las normas estatales, que tienen efectivamente un contenido tuitivo sin alcanzar a los contratos de trabajo, a los convenios colectivos, ni a las normas estatales no tuitivas"17. También Alonso Olea y Casas Bahamonde, restringen su aplicación a normas protectoras y, en todo caso, sólo a dudas sobre dichas normas ${ }^{18}$. La misma opinión se aprecia en Palomeque y Álvarez, quienes lo conciben como un criterio de interpretación normativo con un reducido campo de actuación y se debe aplicar "no como método primero sino último en el razonamiento" ${ }^{\prime 1}$. Incluso se ha llegado a dudar de su función como criterio de interpretación ${ }^{20}$.

Si la norma favorece determinados intereses contractuales, "no puede extenderse tal tutela a su aplicación, pues de otra forma pueden producirse verdaderas arbitrariedades y una situación de inseguridad jurídica, radicalmente incompatible con el Estado de Derecho"21. Es decir, no cabe atribuir a una norma, que de por sí es tuitiva del trabajador, un sentido o alcance más amplio que aquel que tuvo en vista el legislador al dictarla. En este sentido un juez no podría legítimamente extender su aplicación a situaciones no previstas para así «crear» un derecho aún más protector. Asimismo, cuando las normas laborales sean neutras o protegen el interés de la empresa, no pue-

\footnotetext{
3 Sagardoy Bengoechea, Juan Antonio, et al. Prontuario de Derecho del Trabajo -8a edición-. Navarra, Aranzadi, 2006, p. 100.

14 Cessari, Aldo, op. cit. (n. 9), pp. 11-25.

15 Montoya Melgar, Alfredo, op. cit. (n. 1), p 222.

16 Sagardoy Bengoechea, Juan Antonio; et al, op. cit., (n. 13), p. 100.

7 Desdentado Bonete, Aurelio, op. cit (n. 12), p. 105 y ss.

18 Alonso Olea, Manuel; Casas Bahamonde, M. Emilia. Derecho del Trabajo -24a edición-. Madrid, España: Aranzadi, 2006, pp. 1068 y 1069.

19 Palomeque López, Manuel Carlos; Álvarez De La Rosa, Manuel. Derecho del Trabajo -21 a edición-. Madrid, España: Editorial Universitaria Ramón Areces, 2013, pp. 313-314.

20 Mercader Uguina, Jesús R., op. cit. (n. 3), p. 41.

21 Garcia Fernandez, Manuel. Manual de Derecho del Trabajo. Barcelona, España: Editorial Ariel, Barcelona, 1990 , pp. 352 y 353 .
} 
den ser interpretadas pro operario sin incurrir en un grave error ${ }^{22}$. "La misión tuitiva ha de ser desarrollada por el legislador con su conocimiento de las circunstancias sociales; la misión del juez no puede estar enturbiada por una inclinación previa hacia una de las partes"23. "Las soluciones fundadas en un automatismo clasista: in dubio pro o contra alguien son a la vez demasiado rígidas y demasiado simples, porque rompen el equilibrio entre el juego de los criterios interpretativos $y$ la libertad de elección del intérprete"24.

Sin embargo, este criterio interpretativo no se traduce en una libertad absoluta para que el juez resuelva discrecionalmente como se le ocurra, "no da derecho a hacer cualquier cosa en nombre de la protección del trabajador ni mucho menos sustituirse al creador de las normas" ${ }^{25}$. Este es un peligro del que los jueces deben alejarse bajo el riesgo de atentar de uno de los fines del derecho, cual es la seguridad jurídica, que sin lugar a duda es preminente ${ }^{26}$. El juez no tiene una facultad discrecional, absoluta y soberana para interpretar, no realiza una interpretación discrecional sino vinculada a la norma. Dicha vinculación asegura la certeza y la seguridad jurídica, sin perjuicio que sus facultades de valorización impiden que el derecho quede estancado ${ }^{27}$.

En un criterio, que hoy parece más bien superado, autores como Plá le otorgan a la regla del in dubio pro operario un papel -también limitado- en la determinación del sentido y alcance de normas oscuras. "No se trata de corregir la norma, ni siquiera de integrarla: sólo cabe utilizar esta regla cuando existe una norma y únicamente para determinar el verdadero sentido dentro de varios posibles". Ante la ausencia de norma "no es posible recurrir a este procedimiento para sustituir al encargado de dictarla, y mucho menos es posible apelar a esta regla, para apartarse del significado claro de la norma. O para atribuirle un sentido que no se puede desprender de ninguna manera de su texto ni de su contexto"28. La determinación de la intención o espíritu de la norma, es un concepto absolutamente objetivo. No cabe aquí un subjetivismo que resultaría de buscar una supuesta voluntad del legislador ni tampoco el subjetivismo del intérprete, al que corresponde sólo reconstruir el sentido de la ley, tarea en que no deben influir preferencias personales de carácter contingente o arbitrario ${ }^{29}$. Plá manifiesta su coincidencia con Mario de la Cueva, en cuanto interpretar la ley no es crearla y el desconocimiento de esta regla ha sido la causa de multitud de cambios de jurisprudencia, pues la Corte ha mutado la forma de pensar para conceder a los trabajadores ventajas económicas que no están consignadas en ninguna norma ${ }^{30}$. En todo caso, no se asigna al principio protector un rol integrador como si lo tienen los principios generales del derecho, ya que no cabe su inclusión dentro esta categoría ${ }^{31}$.

\footnotetext{
22 Desdentado Bonete, Aurelio, op. cit. (n. 12), p.105.

23 Sagardoy Bengoechea, Juan Antonio, et al, op. cit. (n. 13), p. 101.

24 Desdentado Bonete, Aurelio, op. cit. (n. 12), p. 99.

25 Pla Rodriguez, Américo. Los Principios del Derecho del Trabajo -3a edición-. Buenos Aires. Argentina: Ediciones Depalma, 1998, p. 77.

26 García Fernández, op. cit. (n. 21), pp. 352 y 353.

27 Dúcci Claro, Carlos. Interpretación Jurídica -3a edición-. Santiago, Chile: Editorial Jurídica de Chile, 1997, p. 122.

28 Plá Rodríguez, Américo, op. cit. (n. 25), p. 88.

29 Ducci Claro, Carlos, op.cit. (n. 27), p. 122.

30 Plá Rodríguez, Américo, op. cit. (n. 25), p. 89.

31 Alonso Olea, Manuel; Casas Bahamonde, M. Emilia, op. cit. (n. 18), pp. 1070 y ss. No mencionan dentro de los principios generales del derecho al principio protector y lo restringen a una dimensión interpretativa muy limitada en pp. 1068 y ss.
} 


\section{LA DOCTRINA NACIONAL}

Nuestra doctrina, siguiendo estrechamente a Plá, sostiene que el principio protector orienta el derecho laboral y la "regla in dubio pro operario" sería una expresión de éste en el ámbito interpretativo. El Juez, entre varios sentidos posibles, debe preferir aquel que sea más favorable al trabajador $^{32}{ }_{-}^{33}$. Thayer y Novoa agregan que al aplicarse el in dubio pro operario como criterio interpretativo se debe preferir la interpretación que refleje el espíritu de la ley. Además, no sólo debe tenerse presente los intereses de los trabajadores sino que se deben armonizar "con los de la comunidad; y que una postura menos proteccionista puede acomodarse mejor con la eficacia del derecho ${ }^{34}$. Se previene que los jueces no pueden recurrir a él para "mejorar los preceptos existentes"35. Gamonal alejándose del resto de la doctrina afirma que el principio protector permitiría integrar lagunas, creando el juez una norma para el caso $^{36}{ }_{-}^{37}$.

\section{JURISPRUDENCIA RECIENTE}

Nos abocaremos a dos problemas en cuya resolución se ha invocado el in dubio pro operario.

\subsection{LA CADUCIDAD EN EL DESPIDO INDIRECTO}

El artículo 171 del Código del Trabajo se refiere a la institución denominada despido indirecto o autodespido. Corresponde a una verdadera resolución del contrato por parte del trabajador con motivo de un incumplimiento contractual del empleador. Establece que, en caso de ser el empleador quien incurra en las causales de cesación de los números 1, 5 o 7 del artículo 160 del mismo Código, "el trabajador podrá poner término al contrato y recurrir al juzgado respectivo, dentro del plazo de sesenta días hábiles, contado desde la terminación". Esta disposición, a diferencia del artículo 168 del Código del Trabajo que permite al trabajador despedido recurrir al juez para que declare que su despido fue injustificado, indebido o improcedente, no contempla la suspensión del plazo para demandar al empleador. Como es sabido, la suspensión de la caducidad de la acción de despido sólo es admisible cuando así lo establece la Ley y por el plazo que señala la misma ${ }^{38}$. Luego, si no existe disposición legal que la establezca los supuestos de suspensión de la misma, no

\footnotetext{
32 Lanata Fuenzalida, Gabriela. Contrato Individual de Trabajo -4a edición-. Santiago, Chile: Legal Publishing, 2010 , pp. 47 y 48.

33 Humeres Noguer, Héctor. Derecho del Trabajo y de la Seguridad Social. T. I -18 a edición-. Santiago, Chile: Editorial Jurídica de Chile, 2009, p. 32.

34 Thayer Arteaga, William; Novoa Fuenzalida, Patricio. Manual de Derecho del Trabajo. T II -4a edición-. Santiago, Chile: Editorial Jurídica de Chile, 1998, pp. 27-29.

35 Gaete Berríos, Alfredo. Tratado de Derecho del Trabajo y Seguridad Social. T. I. Santiago, Chile: Editorial Jurídica, 1966, p. 54.

36 Gamonal Contreras, Sergio. Fundamentos de Derecho Laboral -3a edición-. Santiago, Chile: LegalPublishing, 2011, pp. 106 y ss.

37 Gamonal Contreras, Sergio, "El Principio de Protección del Trabajador en la Constitución Chilena", en Estudios Constitucionales, Año 11. $\mathrm{N}^{\circ}$ 1, pp. 425-458. Santiago, Chile: Centro de Estudios Constitucionales, Universidad de Talca, 2013.

38 GiL y GIL, José Luis. La prescripción y la caducidad en el contrato de trabajo. Granada, España: Comares, 2000 , p. 169.
} 
podrían ser objeto de creación judicial. Ello se justifica porque el fundamento de la caducidad es la seguridad jurídica ${ }^{39}$.

La Corte Suprema ha resuelto que:

"La interpretación armónica de los artículos 168 y 171 del Código del Trabajo permite concluir que en el caso del 'autodespido' el plazo para reclamar en sede judicial se suspende en el evento que se efectúe un reclamo ante la Inspección del Trabajo, dado que no existe razón de ninguna índole que permita sostener un diferente tratamiento jurídico para el despido y el 'autodespido', en lo concerniente a la forma como se deben computar los plazos para impetrar las acciones pertinentes".

Pasa enseguida a fundar su decisión en: "el denominado 'Principio Protector', que en materia de interpretación de enunciados normativos se manifiesta en el 'in dubio pro operario', conforme al cual los jueces en caso de duda debieron recurrir en elección de la exégesis la más favorable al trabajador" 40 .

Como se ha visto la norma en análisis, artículo 171 del Código, no contiene referencia alguna, directa o indirecta, a la suspensión del plazo de caducidad. Además, no se observa en ella remisión a la norma de suspensión del artículo 168. De esta manera, la Corte habría creado una regla de suspensión donde la ley no la contempla. No ha existido una labor integradora por cuanto estamos en presencia de una norma que establece un plazo de caducidad sin posibilidad de suspensión y no de un vacío legal. Como acertadamente ha dicho la Corte de Apelaciones de Santiago "Una conclusión distinta llevaría a entender que donde la ley no ha dicho algo estaría necesariamente manifestando una intencionalidad que tendría que ser proclive a los intereses del trabajador" y "tampoco se está ante un caso donde tenga cabida el criterio «in dubio pro operario", porque éste actúa cuando realmente una norma (el artículo 171) puede ser interpretada de diversas manera, cuando hay una verdadera duda" ${ }^{31}$. La misma Corte Suprema había dicho con anterioridad "de acuerdo con el artículo 19 del Código Civil, cuando la norma es clara no debe desatenderse su tenor literal. Por lo que no resulta procedente, como se ha hecho en el caso en estudio, recurrir a la aplicación del denominado principio pro operario o a otras normas dentro del mismo texto normativo"42.

Por lo que se ha expuesto, no cabría sino concluir que la acertada aplicación del artículo 171 el Código del Trabajo excluye la posibilidad de suspensión del plazo. No es posible crear un caso de suspensión del mismo sobre la base de una improcedente invocación del denominado in dubio pro operario. Ello porque, aún aquellos que sostienen la procedencia de dicha regla de interpretación, no la consideran aplicable para la integración legal y menos para modificar la ley.

\footnotetext{
39 Godino Reyes, Martín. "Caducidad del Despido en El Despido Disciplinario". En: Gil y Gil. José Luis; DEL VALLE, José Manuel (coor.). Homenaje al Profesor Juan Antonio Sagardoy Bengoechea. Madrid, España: Ediciones Madrid, Cinca, p. 307.

40 CS, rol 4317-2014,12-05-2014 y CS, rol 21.966-2014, 2-10-2014 (ambas sentencias dictadas en recursos de queja).

41 CA Santiago, rol 1320-2014, 03-10-2014.

42 CS, rol 3105-2012, 26-07-2012.
} 


\subsection{ResPonsABILIDAD DE LA EMPRESA PRINCIPAL RESPECTO DE LA INDEMNIZACIÓN DE PERJUICIOS EN ACCIDENTE DEL TRABAJO}

De conformidad al artículo 1511 del Código Civil las fuentes de la solidaridad son la convención, el testamento y la ley. Existiendo pluralidad de sujetos, la mancomunidad es la regla general. Consecuencias de ello son las siguientes: la solidaridad no se subentiende ni puede aplicase por analogía; quien alegue que existe solidaridad debe demostrarlo, y; las normas que la establezcan deben interpretarse restrictivamente ${ }^{43}$.

El Código del Trabajo, artículo 183-B, establece la responsabilidad solidaria de la empresa principal por las obligaciones de dar que correspondan a los contratistas en favor de sus trabajadores. La misma responsabilidad cabe a los contratistas respecto de las obligaciones de dar de los subcontratistas. La norma no contempla solidaridad por las obligaciones de hacer que afecten a los contratistas, o en su caso, a los subcontratistas, como sería el deber de la empresa principal de protección de la vida y salud de todos los trabajadores que laboran en su empresa o faena de los artículos $183-\mathrm{E}^{44}$ en relación con el artículo 184 del Código del Trabajo.

La Corte Suprema, modificando su criterio ${ }^{45}$, ha dicho que la responsabilidad de la empresa principal, por la indemnización de perjuicios por un accidente del trabajo impuesta a un contratista suyo, sería solidaria. Señala que, "aún ante el silencio de la ley en la asignación expresa del régimen de responsabilidad al que se encuentra sujeto el dueño de la obra cuando es demandado conjuntamente con el contratista", por los daños derivados de un accidente del trabajo, "conforme al principio pro operario que posibilita la integración de las normas que regulan una misma materia, fuerza a concluir que tal estatuto es el propio de la solidaridad". Agrega, "no puede conculcarse con lo resuelto los artículos 1511 y 1526 del Código Civil, por cuanto la interpretación que se ha dado a las normas en análisis es la que permite su máxima expresión protectora, coherente con los fines tenidos en consideración para su elaboración" ${ }^{36}$.

Como se ha explicado, las normas que establecen solidaridad deben ser entendidas de manera restrictiva. Tal sería el caso del artículo 183 B del Código del Trabajo y, por ello no podría extenderse a situaciones no previstas en él. No es, como señala la sentencia, un caso de integración, porque no existe un vacío legal: más bien se estaría creando un caso de solidaridad no previsto en la ley, lo cual no correspondería hacer a una sentencia judicial. Tampoco, por tratarse de normas civiles, cabría interpretar los y b 1511 y 1526 del Código Civil utilizando el in dubio pro operario ${ }^{47}$.

Como argumento secundario la sentencia a que nos abocamos agrega que "en último término, el pago de la indemnización establecida en autos por daño moral convierte el deber de cuidado infraccionado en uno de tal carácter"48, esto es, se convertiría en una obligación da dar. Esta afirmación contradice a nuestra doctrina civilista y normas expresas del Código Civil. La

\footnotetext{
43 Peñallillo Arévalo, Daniel. Obligaciones. Teoría General y Clasificaciones. Santiago, Chile: Editorial Jurídica de Chile, 2003, p. 255.

44 El artículo 183-E obliga a la empresa principal a "adoptar las medidas necesarias para proteger eficazmente la vida y salud de todos los trabajadores que laboran en su obra, empresa o faena, cualquiera sea su dependencia".

45 CS, rol 5.620-2012, 27-03-2013.

46 CS, rol 10.139-2013, 10-06-2014.

47 Dice la sentencia que las "instituciones del derecho civil abordadas por ellas [normas laborales] deben serlo bajo el prisma del Derecho del Trabajo".

48 CS, rol 10.139-2013, 10-06-2014.
} 
obligación de indemnizar perjuicios es la misma obligación que dejó de cumplirse y que ante el incumplimiento cambia de objeto $^{49}$, por lo tanto siempre correspondería a una obligación de hacer.

\section{CONCLUSIONES}

1. En el derecho europeo -España, Alemania, Francia e Italia- el principio protector no tiene aplicación en la interpretación de normas laborales y menos en la integración de lagunas.

2. Sólo al legislador le correspondería dictar normas protectoras del trabajador.

3. El in dubio pro operario no es un principio del Derecho del Trabajo sino un criterio de interpretación y que sólo cabría aplicar ante normas claramente tuitivas.

4. El in dubio pro operario carece de vigencia en la doctrina y jurisprudencia europeas.

5. En los pocos casos en que se admite su aplicación se sostiene que debería hacerse de manera muy limitada, jamás como una herramienta inicial de aproximación al entendimiento de la norma sino solamente como criterio último de razonamiento.

6. No cabría atribuir a una norma que de por si es tuitiva del trabajador un sentido o alcance más amplio que aquel que tuvo en vista el legislador al dictarla. El juez no podría legítimamente extender su aplicación a situaciones no previstas para asi "crear" un derecho aún más protector.

7. El juez no debe actuar con un prejuicio pro o contra una de las partes bajo riesgo de afectar gravemente su imparcialidad y la seguridad jurídica.

8. El in dubio pro operario y el denominado principio protector no se pueden utilizar para integrar lagunas legales.

9. El in dubio pro operario y el denominado principio protector no podrían ser considerados para determinar la competencia de un tribunal o la existencia o no de los requisitos para la procedencia de un recurso o acción laboral y, en general, en lo relativo a aspectos procesales de un caso.

10. El in dubio pro operario, no podría utilizarse como criterio interpretativo de normas civiles que pudiesen incidir en un litigio laboral, Su interpretación debe regirse por las normas comunes sobre interpretación de la ley.

11. No pareciera acertado el criterio de las sentencias comentadas. El in dubio pro operario no puede ser invocado por el juez para crear una situación de suspensión del plazo de caducidad de la acción o un caso de solidaridad no previstos en la ley.

\section{BIBLIOGRAFÍA}

Abelliuk Manasevich, René. Las Obligaciones, t. II -3a edición-. Santiago, Chile: Editorial Jurídica de Chile, 2003.

Alonso Olea, Manuel; Casas Bahamonde, M. Emilia. Derecho del Trabajo -24a edición-. Madrid, España: Aranzadi, 2006.

CESSARI, Aldo. Il favor verso il prestatore di lavoro subordinato. Milan, Italia: A. Giuffre, 1966

Chalaron, Yves. "Lapplication de la disposition la plus favorable". En: Etudes offertes a Gérard Lyon-Caen. París, Francia, Dalloz; 1989.

De la Villa Gil, Luis Enrique. "Presentación". En: de la Villa Gil, Luis Enrique; Lopez Cumbre, Lourdes (dir.). Los Principios del Derecho del TrabajoMadrid, España: Centro de Estudios Financieros, 2003.

49 Abelliuk Manasevich, René. Las Obligaciones. T. II -3a edición-. Santiago, Chile: Editorial Jurídica de Chile, 2003, pp. 726 y 727. 
Desdentado Bonete, Aurelio. El Principio Pro Operario. En: de la Villa Gil, Luis Enrique; Lopez Cumbre, Lourdes (dir.). Los Principios del Derecho del Trabajo. Madrid, España: Centro de Estudios Financieros, 2003.

Ducci Claro, Carlos. Interpretación Jurídica -3a edición-. Santiago, Chile:Editorial Jurídica de Chile, 1997.

GaEte Berríos, Alfredo. Tratado de Derecho del Trabajo y Seguridad Social. T. I. Santiago, Chile: Editorial Jurídica, 1966. Gamonal Contreras, Sergio. Fundamentos de Derecho Laboral -3ª edición- Santiago, Chile: LegalPublishing, 2011.

Gamonal Contreras, Sergio. "El Principio de Protección del Trabajador en la Constitución Chilena", en: Estudios Constitucionales, Año 11. N ${ }^{\circ}$ 1, pp. 425- 458. Santiago, Chile: Centro de Estudios Constitucionales, Universidad de Talca, 2013.

García Fernández, Manuel. Manual de Derecho del Trabajo. Barcelona, España: Editorial Ariel, Barcelona, 1990.

García-Perrote Escartín, Ignacio. Manual de Derecho del Trabajo -3a Edición-. Valencia, España: Tirant Lo Blanch, 2018.

GIL y GiL, José Luis. La prescripción y la caducidad en el contrato de trabajo. Granada, España: Comares, 2000.

Godino Reyes, Martín. "Caducidad del Despido en El Despido Disciplinario". En: Gil y GiL. José Luis; Del VALLE, José Manuel (coor.). Homenaje al Profesor Juan Antonio Sagardoy Bengoechea. Madrid, España: Ediciones Cinca, 2009.

Hanau, Peter; Adomelt, Klaus, Arbeitsrecht. München, Alemania: Luchterhand, 2007.

Humeres Noguer, Héctor. Derecho del Trabajo y de la Seguridad Social. T. I -18 a edición-. Santiago, Chile: Editorial Jurídica de Chile, 2009.

Lanata Fuenzalida, Gabriela. Contrato Individual de Trabajo -4a edición-. Santiago, Chile: Legal Publishing, 2010.

Mazzota, Oronzo. "Il diritto del lavoro e le sue fonti", en: Rivista Italiana di Ditiritto del Lavoro, 3, pp. 219 y ss., Italia: Giuffré, 2001.

Mercader Uguina, Jesús R. Los principios de aplicación del Derecho del Trabajo. Valencia, España: Tirant Lo Blanch, 2014.

Montoya Melgar, Alfredo. Derecho del Trabajo -34² Edición-. Madrid, España: Tecnos, 2013.

Palomeque López, Manuel Carlos; Álvarez de la Rosa, Manuel. Derecho del Trabajo -21 a edición-. Madrid, España. Editorial Universitaria Ramón Areces, 2013.

Peñailillo Arévalo, Daniel. Obligaciones. Teoría General y Clasificaciones. Santiago, Chile: Editorial Jurídica de Chile, 2003.

Pla Rodríguez, Américo. Los Principios del Derecho del Trabajo-3a edición-. Buenos Aires, Argentina: Ediciones Depalma, 1998.

Sagardoy Bengoechea, Juan Antonio, et al. Prontuario de Derecho del Trabajo -8 edición-. Navarra, España: Aranzadi, 2006.

Thayer Arteaga, William; Novoa Fuenzalida, Patricio. Manual de Derecho del Trabajo. T II -4a ediciónSantiago, Chile; Editorial Jurídica de Chile, 1998.

Sentencias

Cour de Cassation, Rapport de Mme Bardy, Consellier rapporteur, Arret n ${ }^{\circ} 570$ du 24 octobre 2008.

Cour de Cassation, Chambre Commercial, 17-07-1996, droit social, p. 1049, J. Sabatier.

Corte Suprema, rol 4.317-2014, 12-05-2014.

Corte Suprema, rol 21.966-2014, 2-10-2014.

Corte de Apelaciones de Santiago, rol 1.320-2014, 03-10-2014.

Corte Suprema, rol 3.105-2012, 26-07-2012.

Corte Suprema, rol 5.620-2012, 27-03-2013

Corte Suprema, rol 10.139-2013, 10-06-2014

Corte Suprema, rol 10.139-2013, 10-06-2014 